\title{
Indirect effects of violence
}

Am. J. Pol. Sci. https://doi.org/10.1111/ajps.12415

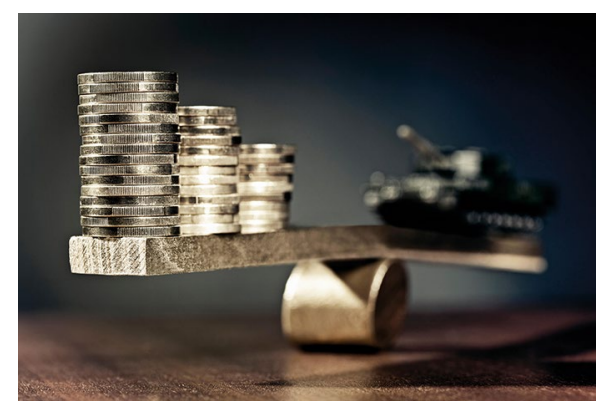

Credit: Klaus Ohlenschlaeger / Alamy Stock Photo

Civilians caught in the midst of political violence face risks from both dissidents and government security forces. However, the danger extends beyond direct physical risk to include indirect effects as well.

New research by Renard Sexton, of Emory University, and colleagues from the University of Texas at Austin, examines one such downstream risk. Using data from Peru, the authors show how government responses to dissident violence create welfare risks to the population as a whole. Following fatal attacks on military personnel, governments often increase security and military programs designed to counter dissident violence. This coercive strategy diverts resources to security needs, at the expense of social programs. In the Peruvian case, the study finds that a single soldier fatality during the budget period leads to a 0.13 percentage point cut to the health budget in the administrative district of the attack. This reduction in the health budget particularly affects women's access to healthcare, which leads to a predicted increase in infant mortality of 76 additional deaths over the following two years.

The study highlights the devastating consequences of political violence, which extend well beyond the direct effects of the violent acts themselves.

Aisha Bradshaw

Published online: 14 March 2019

https://doi.org/10.1038/s41562-019-0568-8 